\title{
Gaze Analysis During Toilet Activity in Elderly People
}

\author{
Yuichi Ishiura, Keizou Numata, Kazuo Higaki \\ Department of Occupational Therapy, School of Health Care Science, Himeji Dokkyo University
}

\begin{abstract}
Background: Toilet activity is performed every day with a physiological phenomenon so called "excretion", which is highly necessary. In this study, we used Eye Mark Recorder, a gaze analyzer, to analyze eye movement of elderly people during toilet activities. In addition, we compared the results with those obtained from a preceding study regarding toilet activities in young people.

Result: The toilet activity was divided into three phases: until they sit down, while they are sitting on the bowl, and until they leave the room. Until they sat down and until they left the room, they were looking at the entire environment in the toilet. While they were sitting on the bowl, however, they were mostly looking forward. A similar tendency was observed in young people as well. Furthermore, retention time, degree of dependence on the lower gaze, rate of recognition, as well as an association between the time required for movement and the degree of dependence on the lower gaze were investigated. The elderly people were far more likely to gaze toward the floor compared to the young people. Conclusions: The results showed which areas the subjects had to look at during 3 toilet-activity phases in order to understand the spatial relation. In toilet activities of the elderly, the rate of gaze toward the floor increased probably due to aging, posture and decreased balancing ability. We will need to further investigate associations between the subjects' age, posture, balancing ability and the gaze during the toilet activities.
\end{abstract}

Keywords: gaze analysis, toilet activity, eye mark recorder

(Asian J Occup Ther 13: 31-40, 2017)

\section{Introduction}

When someone makes decisions somehow in daily activities, there is an eye movement in advance [1]. It has also been reported that eye movement occurs 0.6 seconds before the activity [2], suggesting that there is a close relationship between activities of daily living and visual functions. Wilmut [3] stated that visual information is essential for controlling the limbs, and Crowdy et al. [4] reported on effects of visual control in patients with cerebellar symptoms or unilateral spatial neglect. Hence, we consider that the ability of activity of daily living would be increased or improved by analyzing and understanding the gaze observed before various movements.

The preceding studies regarding visual functions

Received: 10 January 2017, Accepted: 29 May 2017

Corresponding to: Yuichi Ishiura, Department of Occupational Therapy, School of Health Care Science, Himeji Dokkyo University, 2-1, Kamioono 7-chome, Himeji-shi, Hyogo 670-8524, Japan

e-mail: ishiura@gm.himeji-du.ac.jp

(C2017 Japanese Association of Occupational Therapists and daily activities include a study by Ehara et al. [5] on gaze behaviors in cooking activities, a study by Nito et al. [6] on association between visual and upper limb movements while eating with spoons and chopsticks, and a study by Suzuki et al. [7] on visual input during dressing activity in hemiplegia patients. In addition, Land et al. [2, 8, 9] reported studies regarding eye movement when making tea or measurement of eye movement when swinging a baseball bat to hit a ball. However, there is no report available on measurement of gaze in toilet activities.

Toilet activity is performed every day with a physiological phenomenon so called "excretion", which is highly necessary [10]. Suehiro et al. [10] reported that in addition to somatic, vestibular and auditory sensations, visual sensation also plays a significant role in toilet activity. Furthermore, Kimura et al. [11] stated that it is crucial to visually confirm toilet activity throughout the course from the time of taking them to the toilet until the end. In the preceding study [12], we analyzed gaze of young people during toilet activities. The results revealed that, their gaze was mainly in forward direction in both men and women although there was a slight dif- 
ference between them in terms of duration of gaze. We will need to further compare the data obtained from the elderly with those from young people.

For the gaze of the elderly while walking, Itoh et al. [13] reported that they had been mostly looking at the floor or around the feet and frequently gazing toward the floor. In addition, their duration of gaze to watch their steps was longer than that of young people. Itoh et al. [14] also reported that the elderly had relied on the central vision while walking and that their eye-movement range had been broader and stayed lower. These suggest that eye movement of the elderly during toilet activities would be toward the lower direction compared to that of the young people.

The objectives of this study were to reveal the gaze of the elderly during toilet activities and to investigate if there would be any differences between men and women or any features according to sex. The data obtained were further compared with those of young people measured in the preceding study and investigated to find out if there were any differences between the elderly and young people or features according to their age.

\section{Method}

\section{Subjects}

The subjects included 35 healthy elderly adults (hereinafter, the elderly; 17 men and 18 women, the mean age $68.8 \pm 5.7$ years old, using a nearby day-care nursing service center) who had no problem with eye moving in activities of daily living and had submitted oral and written informed consent. We excluded subjects who have problems with visual field or visual eyesight, subjects who could not understand instructions for motions, or subjects whose eye marks could not be detected.

\section{Measuring device}

In this study, we used a hat-shaped gaze analyzer, Eye Mark Recorder (Pupil Centre Corneal Reflection; EMR-8B, nac Image Technology), to measure gaze of elderly people. The device consists of a head unit, controller, Calibration cable, etc. (Fig. 1) and is able to output visual field images with eye mark signals on them. The visual field images were recorded using a digital cassette recorder (GV-HD700, SONY). In addition, the gaze measurements were performed on both eyes. The horizontal angle of the visual field camera lens was $115^{\circ}$. The sampling frequency was $60 \mathrm{~Hz}$.

\section{Method of measurement}

The measurements were performed in a toilet room of about $1.62 \mathrm{~m}^{2}$ in a nearby day-care nursing service

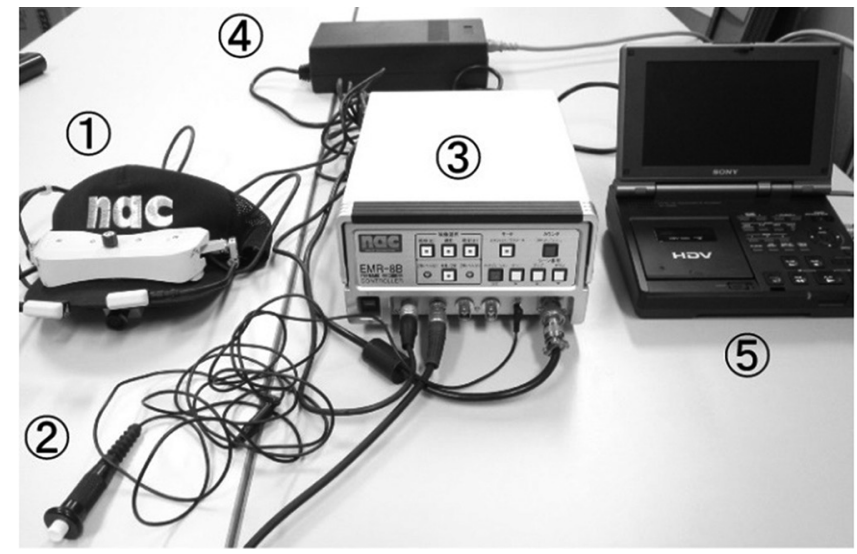

Fig. 1. Eye Mark Recorder System.
(1) Head Unit
(4) $\mathrm{AC}$ adapter
(2) Calibration cable
(3) Controller

center (Fig. 2). The subjects became familiar with the toilet environment and activities before wearing the Eye Mark Recorder in order to avoid the effects of experiences as much as possible. Then they wore the Eye Mark Recorder, and calibration was performed at the point $1 \mathrm{~m}$ away from the toilet door. We observed their various gazes when they are at the toilet door and when they are sitting on the toilet bowl, and examined if there is any shift of eye marks. After calibration, subjects stood up from a chair and waited in front of the door. We recorded their gaze throughout the whole process of opening the door with a starting signal, simulating the movement of putting down the trousers, sitting down on the toilet bowl, sitting still for 5 seconds, and leaving the room. After recording, we analyzed the gaze with EMR-dFactory Ver.1.2 (nac Image Technology).

\section{Analysis method}

The gaze was defined as a line connecting a gaze point and the central fovea of retina, and retention time was defined as the duration of time they are looking at the gaze point. We also defined the condition "one gazed at the point" as a situation where an eye mark stayed within the range of 9 degrees from a point for more than $200 \mathrm{msec}$. Upon analysis, toilet activity was divided into three phases: until they sit down, while they were sitting on the bowl, and until they leave the room, according to the excretion activity model proposed by Yada et al. [15] In each phase, (1) we extracted the gaze points in order to reveal where they were looking at, (2) calculated the rate of retention time in order to find where they were looking at the most (gaze duration/time required for activity $\times 100$ ), and (3) calculated the sum of retention time for the gaze on the floor in each phase, using the 


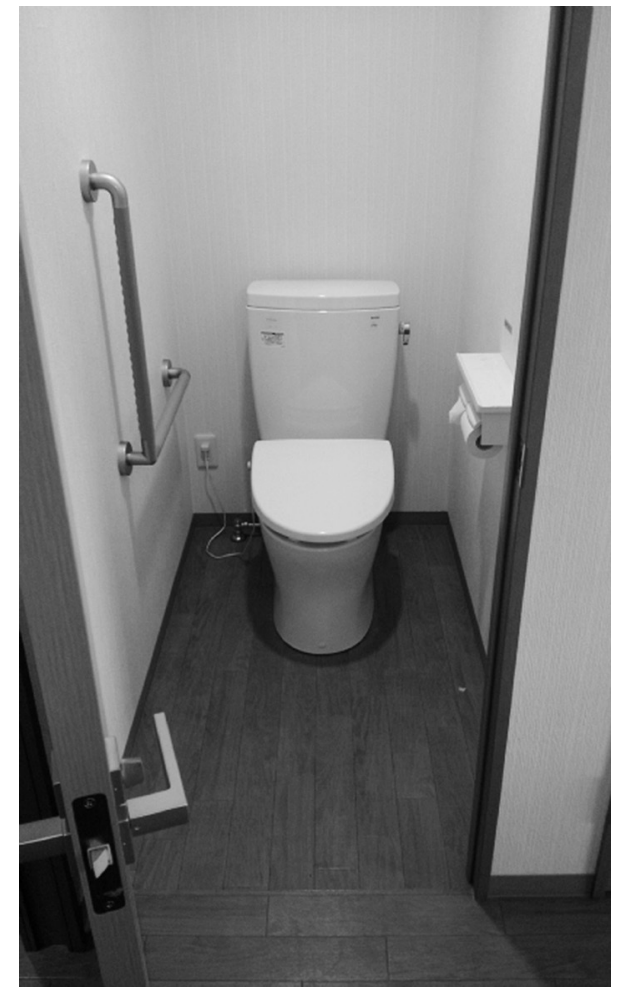

Fig. 2. Appearance of toilet room.

rate of retention time obtained in (2), as the degree of dependence on the lower gaze, (4) calculated the rate of recognition (number of subjects gazed/the total number of subjects $\times 100$ ), on the basis of the study conducted by Katsura et al. [16], in order to find out what were the gaze points looked at by many people as they were crucial for activities, and (5) revealed the association between the time required for activities and the degree of dependence on the lower gaze.

In statistical analysis, Mann-Whitney $U$ test was used in comparisons between elderly men and women for the rate of retention time and the degree of dependence on the lower gaze, as there had been non-normality included in the data. Meanwhile, $\chi^{2}$ test was used in comparison for the rate of recognition. The association between the time required for activities in each phase or for a series of those in all 3 phases and the degree of dependence on the lower gaze was analyzed using the Spearman's rank correlation coefficient. The significance level was set to be $<0.05$. After the tests, we investigated the difference between the elderly and young people from results obtained from the elderly men and women and those of young people.

This study was conducted with approval from the bioethics committee of Himeji Dokkyo University (No.12-04) and the ethical review board of Osaka Prefecture University (2012-OT01).

\section{Results}

Table 1 shows the time required subject's motion in each phase. The results of gaze points of the elderly subjects in each phase and the rate of retention time are shown in Fig. 3 and Table 2. Together, the data of young people [12] is shown in Table 2.

\section{(1) Gaze points}

For men, 17 points until they sat down, 7 points while they were sitting on the bowl, and 18 points until they left the room were extracted. For women, 17 points until they sat down, 8 points while they were sitting on the bowl, and 16 points until they left room were extracted. In men, light switch was not extracted from the phase while they were sitting on the bowl, and in women, the left wall next to the door and the left front wall were not extracted from the phase until they left the room.

The gaze points were very similar to those of young people [12] in each phase, although there were some minor differences. The subjects were likely to look around the entire toilet environment until they sat down or until they left the room. While they were sitting on the bowel, they tended to look forward most of the time.

\section{(2) Rate of retention time}

Until they sat down, the rate of retention time was significantly higher in women than in men for the right wall next to the door $(\mathrm{U}=91.0, p=0.04)$. While until they left the room, the rate of retention time was significantly higher in men than in women for outside the door.

In elderly people, the rate of retention time on the floor was higher compared to that of young people until they sit down and until they left the room. In young people, however, the rate was higher for the wall and toilet bowl, etc. compared to the elderly.

\section{(3) Degree of dependence on the lower gaze in each phase}

The degrees of dependence on the lower gaze in each phase for both elderly and young people [12] are shown in Table 2. In the elderly people, no significant difference was observed between men and women for

Table 1. The time required subject's motion in each phase.

\begin{tabular}{lccc}
\hline & $\begin{array}{c}\text { Until they } \\
\text { sit down }\end{array}$ & $\begin{array}{c}\text { While sitting } \\
\text { on the bowl }\end{array}$ & $\begin{array}{c}\text { Until they } \\
\text { leave the room }\end{array}$ \\
\hline Elderly men & 21.8 & 5 & 33.2 \\
Elderly women & 17.2 & 5 & 27.6 \\
all subjects & 19.5 & 5 & 30.3 \\
\hline
\end{tabular}

Unit: second 

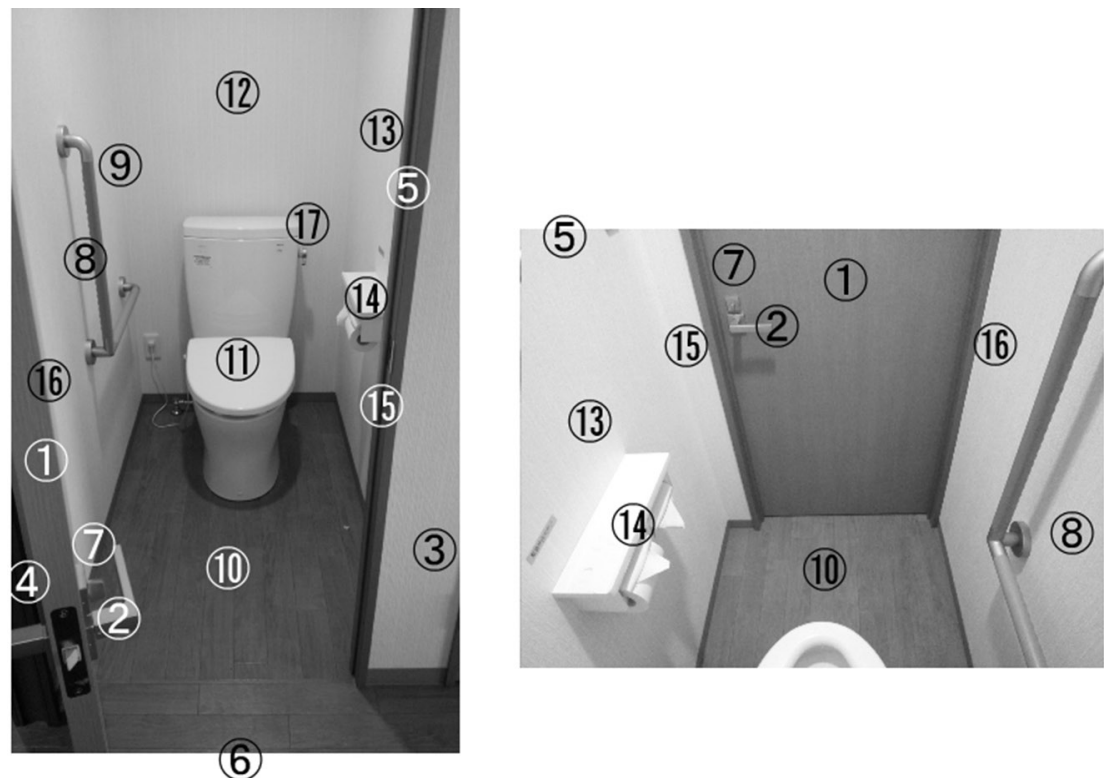

Fig. 3. Extracted gaze points.
(1) Door
(2) Door handle
(3) Right wall next to the door
(4) Left wall next to the door
(9) Handrail
(10) Floor
(11) Toilet bowl
(12) Front wall

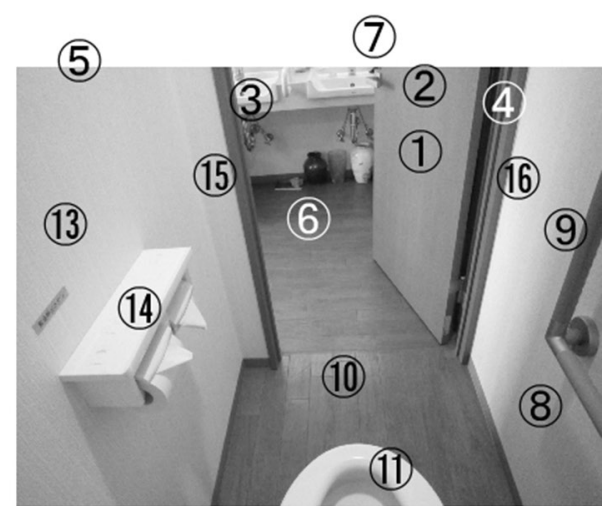

(17) (12) the 3 phases and for the series of activities.

The degree of dependence on the lower gaze was higher in the elderly compared to the young people for the series of activities until they sat down and until they left the room.

\section{(4) Rate of recognition in each phase}

The rates of recognition in each phase for both elderly and young people [12] are shown in Table 3. For the elderly, no significant difference was observed in all 3 phases. For the young people, significant difference was observed in the flush lever $\left(\chi^{2}=0.02, p=0.02\right)$.

When compared between the elderly and young people, the rate of recognition for the floor was lower in the young people than in the elderly. However, it was higher for the handrail, wall, and the flush lever in the young people compared to the elderly. It was also revealed that the young people were more likely to obtain information from various gaze points. While sitting on the bowl, there were some minor differences for the lock, left wall, floor and the toilet roll; the rates varied among individuals. As in the phase until they sat down, the rate of recognition was high for the floor in the elderly in the phase until they left the room.

\section{(5) Association between the time required in each phase and the degree of dependence on the lower gaze}

The association between the time required in each phase and the degree of dependence on the lower gaze for both elderly and young people [12] are shown in Table 4. There was no association between the time required in each phase and the degree of dependence on the lower gaze in the entire elderly people or only in men or in women.

For the phase until they sat down, the association between the time and the degree of dependence on the lower gaze varied among men in young people. However, for the other phases, there was no difference between the young people and the elderly.

\section{Discussion}

\section{(1) Gaze points}

It was revealed that the extracted gaze points were almost the same between the elderly men/women and young people. According to the report made by Miyahira et al. [17] there seemed to be a possibility that gaze points were different between men and women during toilet activities. However, the results of this study suggested that in toilet activities there was hardly any or no difference in gaze points according to sex or age. Further investigation will be required with increased number of subjects.

For phases until they sat down and until they left the room, activities included physical movement of excretion activity model proposed by Yada et al. [15], 
Table 2. Gaze points and rates of retention time.

\begin{tabular}{|c|c|c|c|c|c|}
\hline & $\begin{array}{l}\text { Elderly men } \\
\text { (Young men) }\end{array}$ & $\begin{array}{l}\text { Elderly women } \\
\text { (Young women) }\end{array}$ & \multicolumn{2}{|c|}{ Mann-Whitney U test } & Quartile deviation \\
\hline \multicolumn{6}{|l|}{ Until they sit down } \\
\hline Door & $33.9(25.9)$ & $31.9(30.6)$ & $129.5, p=0.44$ & n.s & 6.3 \\
\hline Door handle & $1.8(1.4)$ & $0.7(1.7)$ & $120.5, p=0.26$ & n.s & 0.8 \\
\hline Right wall next to the door & $3.7(4.0)$ & $5.7(4.4)$ & $91.0, p=0.04$ & $*$ & 3.5 \\
\hline Left wall next to the door & $0.04(0)$ & $0.1(0)$ & $153.0, p=1.00$ & n.s & 0.0 \\
\hline Light switch & $4.3(4.3)$ & $5.6(4.1)$ & $113.5, p=0.19$ & n.s & 2.2 \\
\hline Outside the door & $3.3(5.9)$ & $3.7(4.6)$ & $132.5, p=0.50$ & n.s & 3.4 \\
\hline Lock & $0.6(1.0)$ & $0.7(1.1)$ & $132.0, p=0.40$ & n.s & 0.9 \\
\hline Left wall & $7.5(6.6)$ & $6.2(8.0)$ & $130.5, p=0.46$ & n.s & 3.0 \\
\hline Handrail & $0.3(0.6)$ & $0.4(0.6)$ & $146.5, p=0.81$ & n.s & 0.6 \\
\hline Floor & $10.1(6.3 \%)$ & $8.1(2.5 ※)$ & $106.0, p=0.12$ & n.s & 4.1 \\
\hline Toilet bowl & $12.0(14.4)$ & $10.0(13.9)$ & $120.0, p=0.28$ & n.s & 2.6 \\
\hline Front wall & $3.8(2.5)$ & $3.9(4.0)$ & $128.0, p=0.41$ & n.s & 2.2 \\
\hline Right wall & $13.1(18.2)$ & $16.2(17.0)$ & $115.0, p=0.21$ & n.s & 5.0 \\
\hline Toilet roll & $1.5(1.2)$ & $1.6(1.4)$ & $145.0, p=0.79$ & n.s & 1.4 \\
\hline Right front wall & $3.9(7.1)$ & $5.1(5.6)$ & $148.5, p=0.88$ & n.s & 3.0 \\
\hline Left front wall & $0(0.1)$ & $0(0.3)$ & $153.0, p=1.00$ & n.s & 0.1 \\
\hline Flush lever & $0(0)$ & $0.1(0.2)$ & $144.0, p=0.54$ & n.s & 0.0 \\
\hline Other & $0.3(0.5)$ & $0.01(0)$ & $142.5, p=0.48$ & n.s & 0.0 \\
\hline \multicolumn{6}{|l|}{ While sitting on the bowl } \\
\hline Door & $89.0(88.4)$ & $70.7(85.8)$ & $112.0, p=0.17$ & n.s & 10.0 \\
\hline Door handle & $1.7(3.6)$ & $1.1(3.8)$ & $128.0, p=0.24$ & n.s & 2.2 \\
\hline Light switch & $0(0)$ & $0.1(0)$ & $144.5, p=0.33$ & n.s & 0.0 \\
\hline Lock & $1.6(1.6)$ & $0.1(1.3)$ & $143.5, p=0.61$ & n.s & 0.0 \\
\hline Left wall & $0.8(2.1)$ & $3.2(0.6)$ & $129.0, p=0.19$ & n.s & 0.0 \\
\hline Floor & $0(0.7)$ & $0(3.3)$ & $153.0, p=1.00$ & n.s & 0.0 \\
\hline Right wall & $2.4(1.6)$ & $10.4(2.3)$ & $153.0, p=1.00$ & n.s & 0.6 \\
\hline Toilet roll & $0.8(0.3)$ & $5.7(0)$ & $153.0, p=1.00$ & n.s & 0.0 \\
\hline Right front wall & $3.6(1.8)$ & $7.8(2.7)$ & $153.0, p=1.00$ & n.s & 0.6 \\
\hline Left front wall & $0(0)$ & $0(0.1)$ & $153.0, p=1.00$ & n.s & 0.0 \\
\hline \multicolumn{6}{|l|}{ Until they leave the room } \\
\hline Door & $33.0(29.8)$ & $35.8(32.5)$ & $130.0, p=0.46$ & n.s & 6.5 \\
\hline Door handle & $0.4(0.8)$ & $0.7(1.5)$ & $101.5, p=0.09$ & n.s & 0.9 \\
\hline Right wall next to the door & $0.3(2.0)$ & $1.6(2.8)$ & $94.5, p=0.053$ & n.s & 2.1 \\
\hline Left wall next to the door & $0.1(0)$ & $0(0)$ & $144.0, p=0.78$ & n.s & 0.0 \\
\hline Light switch & $2.8(2.7)$ & $3.5(2.9)$ & $118.0, p=0.26$ & n.s & 1.9 \\
\hline Outside the door & $12.7(13.7)$ & $8.1(11.3)$ & $85.5, p=0.03$ & $*$ & 3.9 \\
\hline Lock & $0.7(0.6)$ & $0.5(0.7)$ & $137.0, p=0.61$ & n.s & 0.3 \\
\hline Left wall & $6.0(2.8)$ & $5.5(3.1)$ & $145.5, p=0.81$ & n.s & 2.9 \\
\hline Handrail & $0.1(0.2)$ & $0.1(0.1)$ & $143.5, p=0.76$ & n.s & 0.0 \\
\hline Floor & $7.6(2.3)$ & $4.4(1.6)$ & $103.0, p=0.10$ & n.s & 1.2 \\
\hline Toilet bowl & $8.6(10.0)$ & $9.2(11.3)$ & $147.0, p=0.86$ & n.s & 3.7 \\
\hline Front wall & $3.1(5.4)$ & $4.8(5.3)$ & $103.5, p=0.10$ & n.s & 2.8 \\
\hline Right wall & $11.9(14.7)$ & $14.0(13.8)$ & $126.5, p=0.39$ & n.s & 3.9 \\
\hline Toilet roll & $8.1(8.3)$ & $7.0(6.9)$ & $139.0, p=0.66$ & n.s & 2.8 \\
\hline Right front wall & $2.7(3.4)$ & $3.4(4.3)$ & $130.0, p=0.46$ & n.s & 1.6 \\
\hline Left front wall & $0.1(0.8)$ & $0(0.1)$ & $144.0, p=0.78$ & n.s & 0.0 \\
\hline Flush lever & $2.1(2.5 \%)$ & $1.6(1.7 ※)$ & $117.0, p=0.25$ & n.s & 1.3 \\
\hline Other & $0.01(0)$ & $0.01(0)$ & $152.5, p=0.99$ & n.s & 0.0 \\
\hline
\end{tabular}

Unit: $\%, *: p<0.05$, n.s: not significant

Number in ( ) are data of young people. Excerpt from reference 12.

※ Significant difference was observed between young men and young women. 
Table 3. Rates of recognition in each phase.

\begin{tabular}{|c|c|c|c|c|}
\hline & $\begin{array}{l}\text { Elderly men } \\
\text { (Young men) }\end{array}$ & $\begin{array}{l}\text { Elderly women } \\
\text { (Young women) }\end{array}$ & $\chi^{2}$ test & \\
\hline \multicolumn{5}{|l|}{ Until they sit down } \\
\hline Door & $100(100)$ & $100(100)$ & $1.0, p=1.0$ & n.s \\
\hline Door hadle & $41.2(20.0)$ & $27.8(19.4)$ & $0.70, p=0.40$ & n.s \\
\hline Right wall next to the door & $58.8(65.0)$ & $83.3(67.7)$ & $0.15, p=0.15$ & $\mathrm{n} . \mathrm{s}$ \\
\hline Left wall next to the door & $0(0)$ & $5.6(0)$ & $1.0, p=1.0$ & n.s \\
\hline Light switch & $94.1(85.0)$ & $88.9(83.9)$ & $1.0, p=1.0$ & n.s \\
\hline Outside the door & $76.5(75.0)$ & $72.2(71.0)$ & $0.01, p=0.92$ & n.s \\
\hline Lock & $11.8(20.0)$ & $16.7(22.6)$ & $1.0, p=1.0$ & n.s \\
\hline Left wall & $88.2(85.0)$ & $77.8(96.8)$ & $0.66, p=0.66$ & n.s \\
\hline Handrail & $0(10.0)$ & $5.6(9.7)$ & $1.0, p=1.0$ & n.s \\
\hline Floor & $88.2(65.0)$ & $83.3(38.7)$ & $1.0, p=1.0$ & n.s \\
\hline Toilet bowl & $100(100)$ & $100(100)$ & $1.0, p=1.0$ & n.s \\
\hline Front wall & $64.7(40.0)$ & $66.7(64.5)$ & $0.05, p=0.81$ & n.s \\
\hline Right wall & $100(90.0)$ & $94.4(100)$ & $1.0, p=1.0$ & n.s \\
\hline Toilet roll & $41.2(15.0)$ & $33.3(32.3)$ & $0.73, p=0.73$ & n.s \\
\hline Right front wall & $82.4(85.0)$ & $72.2(71.0)$ & $0.69, p=0.69$ & n.s \\
\hline Left front wall & $0(0)$ & $0(6.5)$ & $1.0, p=1.0$ & n.s \\
\hline Flush lever & $5.9(0)$ & $5.6(3.2)$ & $1.0, p=1.0$ & n.s \\
\hline Other & $5.9(0)$ & $0(3.2)$ & $0.49, p=0.49$ & n.s \\
\hline \multicolumn{5}{|l|}{ While sitting on the bowl } \\
\hline Door & $100(100)$ & $94.4(96.8)$ & $1.0, p=1.0$ & n.s \\
\hline Door hadle & $5.9(15.0)$ & $16.7(16.1)$ & $0.60, p=0.60$ & n.s \\
\hline Lock & $11.8(10.0)$ & $11.1(3.2)$ & $1.0, p=1.0$ & n.s \\
\hline Left wall & $5.9(10.0)$ & $5.6(3.2)$ & $1.0, p=1.0$ & n.s \\
\hline Floor & $0(10.0)$ & $0(3.2)$ & $1.0, p=1.0$ & n.s \\
\hline Right wall & $5.9(10.0)$ & $27.8(6.5)$ & $0.18, p=0.18$ & n.s \\
\hline Toilet roll & $5.9(0)$ & $11.1(0)$ & $1.0, p=1.0$ & n.s \\
\hline Right front wall & $23.5(13.7)$ & $22.2(16.1)$ & $0.10, p=0.76$ & n.s \\
\hline \multicolumn{5}{|l|}{ Until they leave the room } \\
\hline Door & $100(100)$ & $100(100)$ & $1.0, p=1.0$ & n.s \\
\hline Door hadle & $17.6(30.0)$ & $33.3(41.9)$ & $0.44, p=0.44$ & n.s \\
\hline Right wall next to the door & $23.5(50.0)$ & $50(45.2)$ & $1.61, p=0.20$ & n.s \\
\hline Left wall next to the door & $5.9(0)$ & $0(0)$ & $0.49, p=0.49$ & n.s \\
\hline Light switch & $94.1(80.0)$ & $100(71.0)$ & $0.49, p=0.49$ & n.s \\
\hline Outside the door & $100(100)$ & $88.9(93.5)$ & $0.49, p=0.49$ & n.s \\
\hline Lock & $23.5(20.0)$ & $22.2(16.1)$ & $0.10, p=0.76$ & n.s \\
\hline Left wall & $94.1(55.0)$ & $88.9(51.6)$ & $1.0, p=1.0$ & n.s \\
\hline Handrail & $0(5.0)$ & $0(0)$ & $1.0, p=1.0$ & n.s \\
\hline Floor & $88.2(40.0)$ & $77.8(38.7)$ & $0.66, p=0.66$ & n.s \\
\hline Toilet bowl & $100(95.0)$ & $100(100)$ & $1.0, p=1.0$ & n.s \\
\hline Front wall & $70.6(90.0)$ & $83.3(83.9)$ & $0.44, p=0.44$ & n.s \\
\hline Right wall & $100(100)$ & $94.4(96.8)$ & $1.0, p=1.0$ & n.s \\
\hline Toilet roll & $94.1(95.0)$ & $88.9(90.3)$ & $1.0, p=1.0$ & n.s \\
\hline Right front wall & $88.2(75.0)$ & $66.7(80.6)$ & $0.23, p=0.23$ & n.s \\
\hline Left front wall & $5.9(20.0)$ & $0(3.2)$ & $0.49, p=0.49$ & n.s \\
\hline Flush lever & $88.2(85.0 ※)$ & $72.2(51.6 \%)$ & $0.40, p=0.40$ & n.s \\
\hline
\end{tabular}

unit: $\%, *: p<0.05$, n.s: not significant

Number in ( ) are data of young people. Excerpt from reference 12.

※ Significant difference was observed between young men and young women. 
Table 4. Association between the time required in each phase and degree of dependence on lower gaze.

\begin{tabular}{lccc}
\hline & $\begin{array}{c}\text { Elderly men } \\
\text { (Young men) }\end{array}$ & $\begin{array}{c}\text { Elderly women } \\
\text { (Young women) }\end{array}$ & $\begin{array}{c}\text { All elderly people } \\
\text { (All young people) }\end{array}$ \\
\hline Until they sit down & $-0.21, p=0.15 \mathrm{n} . \mathrm{s}$ & $0.24, p=0.35 \mathrm{n} . \mathrm{s}$ & $0.20, p=0.25 \mathrm{n} . \mathrm{s}$ \\
& $(-0.45, p=0.05 \%)$ & $(-0.07, p=0.71 \mathrm{n} . \mathrm{s})$ & $(-0.20, p=0.15 \mathrm{n} . \mathrm{s})$ \\
Until they leave the room & $-0.33, p=0.20 \mathrm{n} . \mathrm{s}$ & $0.17, p=0.51 \mathrm{n} . \mathrm{s}$ & $0.01, p=0.96 \mathrm{n} . \mathrm{s}$ \\
& $(0.19, p=0.42 \mathrm{n} . \mathrm{s})$ & $(0.19, p=0.32 \mathrm{n} . \mathrm{s})$ & $(0.16, p=0.26 \mathrm{n} . \mathrm{s})$ \\
A series of activities & $-0.23, p=0.39 \mathrm{n} . \mathrm{s}$ & $0.43, p=0.08 \mathrm{n} . \mathrm{s}$ & $0.24, p=0.17 \mathrm{n} . \mathrm{s}$ \\
& $(-0.42, p=0.06 \mathrm{n} . \mathrm{s})$ & $(-0.02, p=0.92 \mathrm{n} . \mathrm{s})$ & $(-0.16, p=0.27 \mathrm{n} . \mathrm{s})$ \\
\hline
\end{tabular}

Values represent Spearman correlation coefficients (rs)

*: $p<0.05$, n.s: not significant

Number in ( ) are data of young people. Excerpt from reference 12.

※ Significant difference was observed between young men and young women.

suggesting that they had to look at a variety of gaze points in order to understand the spatial relation. On the contrary, while they were sitting on the bowl, there was hardly any physical movement, suggesting that they were able to understand the spatial relation with a few gaze points. It was also revealed that this method of understanding the spatial relation was an essential strategy regardless of age. We considered that we may need to practice toilet activities and toilet induction, taking the gaze points in each phase into consideration.

Further investigations will be necessary in the future for each phase in order to assess whether or not postures or activity efficiency would differ between activities looking at the gaze points and those not looking at the gaze points. In addition, we will also need to investigate the differences for gaze points between the simulated activities performed in this study and actual activities.

\section{(2) Rate of retention time}

Significant differences were observed between men's and women's gaze points. Women tended to gaze toward the right wall next to the door until they sat down and for the gaze toward outside the door until they left the room. Generally, women are said to have lower visual cognitive function than men. We think that the men's gaze was directed to something else instead of staying long at the right wall near the entrance. Because, before they sat down, the men perceived the toilet environment faster than the women. Likewise, we think that the proportion of retention time outside the door increased because, before they left the room, the men finished the cognition inside the toilet early and their attention was directed to the outside. These rates of retention time were considered to be a feature of sex difference in toilet activities. We expect the cognitive process for grasping the toilet environment to be revealed by considering the rates of retention time and the gaze movement in future researchers.

As a feature until they sat down, both the elderly people and the young people had higher rates of retention time in the order of the door, the right wall, the toilet bowl, and the floor. As a feature while sitting on the bowl, the rates of retention time at the front was high. As a feature until they left the door, the rates of retention time at the sink levers and the toilet roll were higher than those until they sat down. Moreover, in the elderly, the rate of retention time was high for the gaze toward the floor in both phases until they sat down and until they left room compared to the young people. The rate of retention time for the gaze toward the wall, however, decreased as that for the floor increased. These results appeared characteristic to the gaze during toilet activity in the elderly. It was also suggested that the methods of collecting information to understand the spatial relation might be different between the elderly and young people. We need to reveal how they obtain information by analyzing the details of eye movement during activities.

It is also necessary to assess the elderly with diseases, as the subjects included in this study were healthy elderly adults, and investigate whether or not the rate of retention time for the gaze toward the floor would be different. The association between the retention time and the conduct of activities should be revealed as well.

\section{(3) Degree of dependence on the lower gaze in each phase}

For the degree of dependence on the lower gaze, there was no significant difference observed in each phase between elderly men and women. In the phases until they sat down and until they left the room, it was higher in the elderly than in the young people. It was considered necessary to investigate changes in the degree of dependence on the lower gaze according to each age group. 
Itoh et al. [13] and Kuroiwa et al. [18] stated that the gaze of young people when they were walking tended to be forward while that of elderly people tended to be lower. It was also revealed in this study that the gaze of the elderly was lower than that of young people. Moreover, it has been reported that balancing ability of the elderly was associated with visual sensation, contrast sensitivity, and stereoscopic vision $[19,20]$ and that their ability of maintaining the posture decreased remarkably under the condition where their visual field had been reduced [21]. The more they become dependent on the lower gaze, the more their visual field would be reduced and their ability of maintaining the posture during toilet activity might be affected as well, resulting in onset of falls. We may be able to prevent these falls, leading them to the safe toilet activities, by investigating whether or not if there is a difference in the degree of dependence on the lower gaze between the subjects with the history of falls and those without.

\section{(4) Rate of recognition in each phase}

Until they sat down, the recognition rate was high for the gaze toward the floor in the elderly compared to the young people. However, in young people, it was high for the handrail, wall and flush lever compared to the elderly. These indicate that young people were attempting to obtain information from more various gaze points compared to the elderly. Meanwhile, Itoh et al. [13] reported that, for the elderly people, gaze while walking included eye movement to collect information using visual data as feedforward and activities to observe their own feet movements; the recognition rate for the gaze toward the floor was high in the elderly probably as they attempted to collect information and observe their own feet movements. We need to investigate how the toilet activity of the elderly will be affected if their gaze toward the floor is restricted.

The recognition rates for the toilet bowl, right and left walls, and the light switch were high in both elderly and young people. These points may be important for them to gaze at in order to understand the spatial relation. The recognition rate for the light switch was high probably because it required them to do operation.

The recognition rate for the handrail was low in both elderly and young people. It may depend on frequency of use in their daily lives; it is necessary to further investigate the association between subjects with diseases or subjects whose balancing ability have decreased and the recognition rate for the handrail.

While sitting on the bowl, there was no difference in the recognition rate between the elderly and young people. The higher rates were reported for gaze points around the door located in front of them. However, gaze points with high recognition rates had varied according to subjects; we need to consider that their gaze while sitting on the bowl could be different among individuals. Further investigations will be necessary to find out how the recognition rate is affected by making the duration longer for sitting on the toilet bowl.

In the phase until they left the room, higher tendencies were observed for elderly people to gaze at the light switch, the left wall, the floor, and the flush lever compared to young people. The recognition rate was high for the left wall in elderly men and women; information from the left wall might have been more important in the elderly compared to the young people. We need to investigate whether or not a similar tendency would be observed in a different toilet environment. For the floor, the cognition rate was higher in the elderly than in the young people, probably for the same reason as in the phase until they sat down. The cognition rate for the flush lever was significantly higher in men than in women. This may be associated with how often the flush lever is being used by men and women. Women use the flush lever more often than men; they might have been able to obtain information not with the direct gaze but with the indirect vision. We should further investigate how experiences would affect gaze.

(5) Association between the time required in each phase and the degree of dependence on the lower gaze

Itoh et al. [13] evaluated correlation between the walking speed and the gaze direction toward the floor and around the feet, and reported that significant correlation was observed in the young people but not in the elderly. Furthermore, they also reported that rates of gaze direction toward the floor and around the feet in the elderly might be associated with factors of aging effects such as visual functions which young people do not have or aging effects of physical functions other than walking speed or feet movements. In the preceding study [12], a negative correlation $(\mathrm{r}=-0.45)$ was observed between time and the degree of dependence on the lower gaze in young men, while in the elderly, no significant correlation was observed. These results correspond to those reported by Ito et al. It was therefore suggested that the degree of dependence on the lower gaze had been affected not by duration of activities but by other factors such as age, posture and balancing ability. We should further investigate how the differences in posture or balancing ability would affect gaze in the future.

\section{Conclusions}

In this study, we analyzed gaze of elderly people during toilet activities and investigated characteristics according to their age or sex. The results were further 
compared with data obtained from young people in the preceding study. The gaze points were almost the same for the elderly and young people. It was considered that they might need to look at the entire toilet environment until they sit down or until they leave the room, and while they are sitting on the bowl, they may need to look forward in order to understand the spatial relation. Furthermore, comparisons were made between the elderly and young people for rates of retention time, degrees of dependence on the lower gaze, recognition rates, as well as associations between time required in each phase and the degree of dependence on the lower gaze. According to the results, the rate of retention time was high for the gaze toward the floor. This was probably due to their age, posture and decreased balancing ability rather than duration of the movement. In the future, we should investigate a method of intervention for subjects to safely perform toilet activities by revealing how activities would change if gaze points were limited during the toilet activity, how toilet environment change would affect gaze, and relationship between balancing ability and gaze.

\section{Limitation}

The Eye Mark Recorder used in the gaze analysis had a wire cable. This might have affected the toilet activity. Some activities such as putting up and down the trousers, wiping the buttocks, and flushing the toilet were simulations. The results need to be compared with those obtained for gaze in actual activities. Duration of sitting on the toilet bowl had been assessed in advance and determined. However, it may vary according to the subjects; we should also investigate how gaze would be affected if the duration was longer.

Acknowledgements: We appreciate all participants in this study for their cooperation and staff members of "Akatonbo", the day service rehabilitation center, for letting us use their toilet for the measurement purpose. We also would like to appreciate Professor Norikazu KONISHI from Himeji Dokkyo University, Department of Occupational Therapy, School of Health Care Sciences for his guidance in preparation of this article.

\section{References}

[1] Yamanaka K, Nakanishi Y, Kawakami M. Differences of eye movement on visual information processing between younger and elderly person. Japan Society of Physiological Anthropology. 2008; 13: 39-48.

[2] Land M, Mennie N, Rusted J. The roles of vision and eye movements in the control of activities of daily living.
Perception. 1999; 28: 1311-28.

[3] Wilmut K, Wann JP, Brown JH. How active gaze informs the hand in sequential pointing movements. Exp Brain Res. 2006; 175: 654-66.

[4] Crowdy KA, Kaur-Mann D, Cooper HL, Mansfield AG, Offord JL, Marple-Horvat DE. Rehearsal by eye movement improves visiomotor performance in cerebellar patients. Exp Brain Res. 2002; 146: 244-47.

[5] Ehara T, Matuura A, Hayasi K. Visual axis and a behavioral characteristic when the stroke patients on parietal lobe cooke. [Japanese] Abstract Book 2010/The 44th Japanese Occupational Therapy Congress and Expo (MIYAGI). 2010; P107.

[6] Nitou M, Nakai M, Satou T, Hirayama K, Fujii H. Relationship between visual axis and upper extremity motion during eating by spoon and chopsticks. [Japanese] Abstract Book 2011/The 45th Japanese Occupational Therapy Congress and Expo (SAITAMA). 2011;P26039.

[7] Suzuki Y, Fujii H, Fukuda E. Characteristic of the visual axis during dressing motion in hemiplegic subjects. [Japanese] Abstract Book 2010/The 44th Japanese Occupational Therapy Congress and Expo (MIYAGI). 2010;O83.

[8] Land M, Hayhoe M. In what ways do eye movements contribute to everyday activities? Vision Research. 2001; 41: 3559-65.

[9] Land M, McLeod P. From eye movements to actions: how batsmen hit the ball. Nat Neurosci. 2000; 3: 13405.

[10] Suehiro K, Ishihama T, Gotoh A. Considerations for Toilet Activity. [Japanese] J Kansai Phys Ther. 2008; 8: $7-11$.

[11] Kimura N, Asao A, Ban M, Yamamoto S. Juudokatamahikanja ni okeru toire-katsudo heno kakawari - sumuuzu na jihainyo ni tsunagaru toire-kankyo heno tekiou toha: Rinshou sagyou ryouhou. [Japanese] 2012; 9: 103-9.

[12] Ishiura Y, Numata K, Higaki K. Analysis of gaze under toilet activities in young healthy adults. [Japanese] Japanese Journal of Occupational Therapy Research. 2015; 18: $51-7$.

[13] Itoh N, Fukuda T. A study for age effects in reliance on lower visual information of environment while walking: The sequential change of eye movements. [Japanese] The Japanese journal of ergonomics. 2001; 37: 29-40.

[14] Itoh N, Fukuda T. Experimental analysis of age dependence on two visual systems for walking control. [Japanese] The Japanese journal of ergonomics. 2002; 38 (Supplement): 420-1.

[15] Yada F, Murayama M, Tanaka M, Nagasaka Y, Ogawa T. Examination of senior citizen's home recuperateion continuance factor The second report: The study focusing on process of evacuation action. [Japanese] Archives of Yamagata Prefectural University. 2011; 4: 107-12.

[16] Katsura T, Miura N, Takahashi Y, Hisamoto S, Hoshino A, Usui K, et al. Visual Recognition on Risk of Falling by Visual Attention during Descending Stairs by the Aged -Comparison of Visual Attention Point between Old 
Aged, Middle Aged and Young Aged-. [Japanese] Health Science: Annual Reports of Human Health Sciences, Graduate School of Medicine, Kyoto University. 2008; 5: $1-7$.

[17] Miyahira A, Morita K, Yamaguchi H, Morita Y, Maeda H. Gender differences and reproducibility in exploratory eye movements of normal subjects. Psychiatry Clin Neurosci. 2000; 54: 31-6.

[18] Kuroiwa M, Okazaki S, Yoshioka Y. Comparison of visual behaviors within a normal visual field and a restricted visual field :navigating a corridor and staircase. [Japanese] The Japanese Journal of Ergonomics. 2001; 37: 29-40.
[19] Lord SR, Menz HB. Visual contribution to postural stability in older adults. J Gerontol. 2000; 46: 306-10.

[20] Chandler JM, Duncan PW. Balance and falls in the elderly: Issues in evaluation and treatment. Geriatric Physical Therapy (Guccione AA ed). Mosby-Year Book Inc; 1994: 237-51.

[21] Manchester D, Woollacott M, Zederbauer-Hylton N, Marin O. Visual, vestibular and contribution to balance control in the older adults. The J Gerontol. 1989; 44: M118-27. 